\section{GUEST} EDITORIAL

\title{
Looking back to the future:
} the re-emergence of green care

\author{
Dame Sue Bailey
}

Chair of the Children and Young People's Mental Health Coalition: Senior Clinical Advisor Mental Health at Health Education, England, email Sue.Bailey@hee. nhs.uk
Back in the early 1970 s, as a then young trainee in psychiatry, I found myself in the midst of a shift in Western psychiatry from institutional to community care. I recall and regret the loss of the last of the greenhouses, farms, gardens and green spaces embedded within the grounds of large county asylums.

John Muir, a Scottish-American naturalist at the turn of the 19th century, stated, 'thousands of tired, nerve-shaken, over-civilised people are beginning to find out that going to the mountains is going home' (Muir, 1901). From small, safe, green spaces to vast wildernesses, nature has inspired, brought peace and provided space for reflection. More recently, mental health research has returned to a focus on the outdoors (Townsend \& Weerasuriya, 2010). Today, there are multidisciplinary research centres that include psychologists, psychiatrists, epidemiologists, town planners and environmental scientists working together to investigate how nature is beneficial for mental health.

The thematic section of this issue of BJPsych International challenges the current dogma that the best intervention is the most technical and complex. It suggests that reaching back to our roots, engaging with other people in natural settings could and should be a part of everybody's routine. The first paper, by Jo Barton and Mike Rogerson, introduces the concept of nature-based interventions and outlines the evidence base. Then Dan Bloomfield reviews what makes nature-based interventions in mental health successful. Following this there are two accounts of using green spaces in mental health services, from Australia and the UK.
Green care should be prioritised as a potential solution to the current healthcare context of high demand, cost pressures and community fragmentation. Nature-based interventions do not 'cost the earth', are low carbon and are socially progressive, and therefore sustainable (Townsend \& Weerasuriya, 2010). People who engage with nature-based groups can gain much wider benefits than merely symptom reduction. It is these wider benefits that move people from the sick role, which can be hard to leave for many reasons, towards a state of complete physical, mental and social wellbeing.

What could be a better win-win outcome than enabling those with mental illness to find the peace, well-being and sense of self-empowerment that come with being able to work with others as a community in and across green spaces? Any healthy, health-creating society will have to develop these evidenced-based, values-based interventions of natural, green or nature settings, whether this be specifically for those with mental health problems, or more likely also to involve the wider population. Mental health services across the world need to lead this rediscovery of nature-mindedness, to inspire the societies in which we live to grow and sustain the well-being of all, but especially future generations.

\section{References}

Muir, J. (1901) Our National Parks. Read Books (2013).

Townsend, M. \& Weerasuriya, R. (2010) Beyond Blue to Green: The Benefits of Contact with Nature for Mental Health and Well-Being. Deakin University, Australia. Available at http://www.hphpcentral. com/wp-content/uploads/2010/09/beyondblue_togreen.pdf (accessed 23 April 2014).

\section{THEMATIC} PAPER

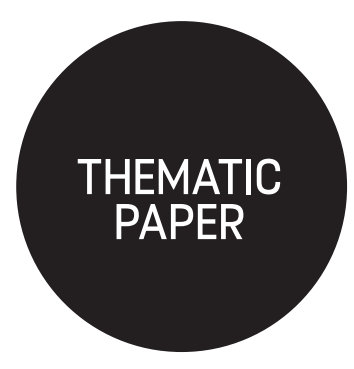

\section{The importance of greenspace for mental health}

\author{
Jo Barton ${ }^{1}$ and Mike Rogerson ${ }^{2}$
}

'School of Sport, Rehabilitation and Exercise Sciences, University of Essex, Wivenho Park, Colchester, Essex, UK, email jobarton@essex.ac.uk

${ }^{2}$ School of Sport, Rehabilitation and Exercise Sciences, University of Essex, Wivenhoe Park,

Colchester, Essex, UK, email mike. rogerson@essex.ac.uk
There is an urgent global need for accessible and cost-effective pro-mental health infrastructure. Public green spaces were officially designated in the 19th century, informed by a belief that they might provide health benefits. We outline modern research evidence that greenspace can play a pivotal role in populationlevel mental health.

\section{Mental health and greenspace}

Mental health conditions are one of the main causes of the overall disease burden worldwide, at an estimated global cost of $£ 1.6$ trillion per year. Health systems across the world have not yet responded adequately to the current burden of mental disorders, and the gap between the need for treatment and its provision is wide. 
Greenspace (sometimes 'green space') is an umbrella term used to describe either maintained or unmaintained environmental areas, which can include nature reserves, wilderness environments and urban parks. Often, particularly in urban contexts, greenspaces are purposefully designated for their recreational or aesthetic merits.

Global urbanisation has reduced access to and engagement with greenspace, but there is good evidence of a positive relationship between levels of neighbourhood greenspace and mental health and well-being. Individuals have less mental distress, less anxiety and depression, greater wellbeing and healthier cortisol profiles when living in urban areas with more greenspace compared with less greenspace. Large differences in disease prevalence are reported when comparing residents of very green and less green settings, even after controlling for socioeconomic status (Maas $e t$ al, 2009). Quantity of nearby greenspace buffers life stresses - a finding demonstrated across ages and cultures, having been observed both in an adult population from the Netherlands and in a childhood population from rural upstate New York, USA (Wells \& Evans, 2003; van den Berg et al, 2010). However, causality is difficult to determine, as self-selection may contribute to the positive relationship between greenspace and better health, because healthier individuals tend to move to or stay in greener neighbourhoods. Nonetheless, individuals who move house from a less green to a more green area have been found to show significantly better mental health in the three post-move years, implying a sustained improvement (Alcock et al, 2014).

Greenspace in the living environment is also associated with lower income-related health inequality, and in the short-term individuals who report high negative mood are more likely also to select a natural area, rather than other types of area, as their favourite place.

Together, these research findings suggest that individuals' desire for contact with nature is not just the result of a romanticised view of nature, but is an important adaptive process, which appears to aid optimum functioning (van den Berg et al, 2007).

\section{Environments shape behaviours}

Environments shape human behaviour - characteristics of individuals and environments act as boundaries within which behavioural invitations or possibilities (termed 'affordances') exist (Brymer \& Davids, 2014). Characteristics of nature environments can promote affordances both for acute positive psychological experiences and for physical activity that in turn promotes well-being. Physical activity in greenspaces has been defined as 'green exercise' (Barton et al, 2016). A positive correlation between greenspace availability and physical activity level has been evidenced in systematic reviews. Indeed, physical activity at least partially mediates the positive relationship between neighbourhood greenspace and mental health and well-being. People who use the natural environment for physical activity at least once per week have about half the risk of poor mental health compared with those who do not do so; and each extra weekly use of the natural environment for physical activity reduces the risk of poor mental health by a further 6\% (Mitchell, 2013). Blue spaces (rivers, lakes and coasts) are as important as green: it is not the colour that matters but the opportunity to behave and respond in a particular way (White et al, 2016).

\section{Acute outcomes of greenspace experiences}

Acute psychological outcomes of time spent in greenspaces have also been reported; beyond greenspaces functioning to promote pro-mental health behaviours, these environments have characteristics that can offer more positive experiences than equivalent time spent in other environments. Simple exposure to nature environments is psychologically restorative and has beneficial influences on individuals' emotions and ability to reflect on life problems. Regarding physical activity, compared with built or indoor settings, green settings enhance exercise-associated improvements in affective state and attentional capacity; laboratory-based research has found that simply viewing simulated nature during exercise can also enhance these outcomes.

\section{The therapeutic application of greenspace for mental health}

Greenspaces are often used in a targeted way to deliver structured therapeutic interventions for vulnerable groups such as youth at risk, individuals living with dementia or mental ill-health, probationers and stressed employees. Interventions include wilderness therapy, social and therapeutic horticulture, facilitated environmental conservation, care farming, ecotherapy, nature-based arts and crafts, and animal-assisted interventions. For example, for adolescents with behavioural or selfesteem issues, wilderness greenspaces are used as vehicles for reflection over week-long expeditions, with relevant psychological and behavioural improvements frequently reported, such as enhanced self-esteem, self-efficacy, self-image, self-control, self-confidence, self-empowerment and decision making. For individuals living with dementia, engaging with greenspaces can positively influence eating and sleeping patterns, fitness and mobility, sense of well-being, self-esteem and control associated with improved social interaction and a sense of belonging. Emotional states are also improved via reductions in stress, agitation, anger, apathy and depression.

Research has gone some way to demonstrating the mechanistic importance of greenspace for mental health. However, to demonstrate the use of greenspace within mental health treatment, robust trials of greenspace interventions are required, of equal rigour to those by which pharmaceutical treatments are judged. 


\section{How and why, or just 'that' greenspace promotes mental health?}

A philosophical point here is whether it matters how and why greenspaces can benefit mental health, or only that it does. The greenspace and health research area should consider directing its efforts along these two complementary agendas. It is clear that engagement with greenspaces offers benefits in terms of mental health and well-being, and thus greenspaces can function as an upstream preventive mental health promotion intervention. Therefore, one agenda of research should be to investigate the potential benefits of greenspace in relation to a range of previously unexplored measures of interest, and to consider how wideranging the benefits might be. The complementary research agenda should comprise examination of the mechanisms that underpin and link the reported beneficial outcomes (Craig et al, 2016).

If greenspace were considered in the same way as a drug for mental health and well-being would be, more detailed understanding of its mechanisms would lead to optimal dosage, and knowledge of when and for whom it might work best. Optimal doses need to account for a wide range of mediators (Shanahan et al, 2015), including:

- environmental factors, both qualitative (e.g. biodiversity, air quality, noise) and quantitative (e.g. tree canopy cover), as well as weather

- personal factors, such as age, gender, beliefs about the value of nature, nature relatedness, prior experiences and childhood memories, as well as perceptions of risk

- social and community factors, including social interaction, trust, ethnic, cultural and social norms, and accessibility of green spaces.

Research indicates that potential mechanisms underpinning the positive relationship between greenspace and health are likely to include sensory-perceptual and immunological processes, air quality, physical activity, stress and social integration.

\section{Conclusion}

Given the current prevalence and costs of worldwide mental ill-health and the concurrent rise in global urbanisation, there is a need for greater interdisciplinary collaboration. It is important to incorporate greenspace into the design of buildings, healthcare facilities, social care settings, homes and communities to create shared spaces which facilitate interaction and attachment, foster well-being, and increase opportunities for green exercise (Kellert, 2016). Green spaces provide vital health services as well as environmental services; they are equigenic, reducing socioeconomic health inequalities, facilitating activity and promoting better mental health and well-being. The integration of biophilic design may provide a cost-effective public health intervention, which promotes the evident positive links between green spaces and mental health.

\section{References}

Alcock, I., White, M. P., Wheeler, B. W., et al (2014) Longitudinal effects on mental health of moving to greener and less green urban areas. Environmental Science and Technology, 48, 1247-1255.

Barton, J., Bragg, R., Wood, C., et al (eds) (2016) Green Exercise: Linking Nature, Health and Well-Being. Routledge.

Brymer, E. \& Davids, K. (2014) Experiential learning as a constraintled process: an ecological dynamics perspective. Journal of Adventure Education and Outdoor Learning, 14, 103-117.

Craig, J. M., Logan, A. C. \& Prescott, S. L. (2016) Natural environments, nature relatedness and the ecological theater: connecting satellites and sequencing to shinrin-yoku. Journal of Physiological Anthropology, 35, 1.

Kellert, S. R. (2016) Nature in buildings and health design. In Green Exercise: Linking Nature, Health and Well-Being (eds J. Barton, R. Bragg, C. Wood, et al), pp. 17-25. Routledge.

Maas, J., Verheij, R. A., De Vries, S., et al (2009) Morbidity is related to a green living environment. Journal of Epidemiology and Community Health, 63, 967-973.

Mitchell, R. (2013) Is physical activity in natural environments better for mental health than physical activity in other environments? Social Science and Medicine, 91, 130-134.

Shanahan, D. F., Fuller, R. A., Bush, R., et al (2015) The health benefits of urban nature: how much do we need? Bioscience, 65 476-485.

van den Berg, A. E., Hartig, T. \& Staats, H. (2007) Preference for nature in urbanized societies: stress, restoration, and the pursuit of sustainability. Journal of Social Issues, 63, 79-96.

van den Berg, A. E., Maas, J., Verheij, R. A., et al (2010) Green space as a buffer between stressful life events and health. Social Science and Medicine, 70, 1203-1210.

Wells, N. M. \& Evans, G. W. (2003) Nearby nature a buffer of life stress among rural children. Environment and Behavior, 35 $311-330$

White, M. P., Bell, S., Elliott, L. R., et al (2016) The health benefits of blue exercise in the UK. In Green Exercise: Linking Nature, Health and Well-Being (eds J. Barton, R. Bragg, C. Wood, et al), pp. 69-78. Routledge.

\section{International Perspectives on Psychiatry Under Restrictive Conditions}

BJPsych International is seeking to survey across the world the practice of psychiatry in restrictive settings and conditions (prisons, jails, on parole, conditional release and community treatment under legal provision) as well as coercive practices in the management of people with a mental illness, beyond psychiatry. The journal, therefore, is inviting authors to submit papers on national or regional aspects of one or more of the above areas, highlighting current practice, relevant data (or lack of the same), training and service needs and areas for future research.

For further information, please contact the deputy editor, George Ikkos, at ikkos@doctors. org.uk 